\title{
Prospective Teachers' Semiotic Conflicts in Computing Probabilities from a Two-Way Table
}

\author{
Carmen Batanero \& José M. Contreras \\ Universidad de Granada, SPAIN \\ Carmen Díaz \\ Universidad de Huelva, SPAIN \\ Ernesto Sánchez \\ Centro de Investigación y Estudios Avanzados, MÉXICO
}

•Received 15 December 2015•Revised 19 April $2015 \bullet$ Accepted 26 April 2015

The aim of this research was to assess the common knowledge of elementary probability in a sample of 183 prospective primary school teachers using and open-ended task, where teachers had to compute simple, compound and conditional probability from data presented in a two-way table. We base on theoretical ideas from the onto-semiotic approach to perform a semiotic analysis, in which we describe the mathematical objects and processes involved in the solutions of the tasks. Participants in the sample showed a weak common knowledge to compute simple, compound and conditional probabilities from a two-way table: they confused simple, compound and conditional probability; exchanged condition and event in conditional probabilities; confused probability and frequency or the union of events with the intersection. The semiotic analysis is used to provide and explanation for these errors in terms of semiotic conflicts. This list of difficulties expands what was found in previous research and may be used to reinforcing the preparation of prospective teachers to teach probability.

Keywords: assessment, simple, compound and conditional probability, teacher knowledge, $2 \times 2$ tables

\section{INTRODUCTION}

Recently, probability has been included in the primary school curriculum in many countries due to the usefulness of probability for daily life, the way in which probability reasoning support decision making and the instrumental role of probability in various curricular areas and professional work (Gal, 2005; Jones, 2005). Moreover, the importance of developing stochastic reasoning in the students is being emphasized in recent curricular documents (e.g., National Council of Teachers of Mathematics [NCTM], 2000; Ministerio de Educación y Ciencia [MEC], 2006, Ministerio de Educación, Cultura y Deporte [MECD], 2014) even for primary

Correspondence: Carmen Batanero,

Facultad de Ciencias de la Educación, Campus de Cartuja, 18071 Granada, Spain.

Phone: 34 958243950; Fax: 958246357

E-mail: batanero@ugr.es

doi: 10.29333/iejme/288 
school levels, where students are expected to perform experiments or simulations, formulate questions or predictions, collect and analyze data from these experiments, propose and justify conclusions and predictions that are based on data (Franklin et al., 2007; NCTM, 2000).

The success of these curricula will depend on the extent to which we can educate these teachers to teach probability. Unfortunately, several authors (e.g., Franklin \& Mewborn, 2006) agree that many of the current programmes still do not train teachers adequately for their task to teach statistics and probability. Teachers also have beliefs about instructional goals regarding probability and how they are linked with instructional content (Eichler, 2011), which will in turn affect how they present topics in statistics and probability. The above reasons suggest to us the relevance of assessing the teachers' educational needs in probability in order to reinforce the specific and the didactic preparation of primary school statistics teachers, when needed.

After Shulman's (1987) reference work, an increasing number of authors have analyzed the nature of knowledge needed by teachers to achieve truly effective teaching outcomes. Ball and her colleagues (Ball, Lubienski, \& Mewborn, 2001; Hill, Ball, \& Schilling, 2008) developed the notion of "mathematical knowledge for teaching" (MKT) in which they distinguished different categories, one of which is relevant for this study. Unfortunately, few research has been carried out related to the specific probabilistic knowledge of teachers.

The aim of this research was to assess Common Content Knowledge (CCK), that is, the mathematical (probabilistic) knowledge teachers are responsible for developing in their students. It can be thought of as the teacher' understanding of probability concepts and how these concepts relate to form the larger body of knowledge. We assess this knowledge in a sample of 183 prospective primary school teachers in Spain, from their solution to an open-ended task where they had to compute a simple, a compound and a conditional probability from data given in a $2 \times 2$ two-way table. Below we first present our theoretical background, then describe the research method, present and discuss the results and conclude with some implications for training teachers to teach probability.

\section{THEORETICAL BACKGROUND}

\section{Mathematical practices, objects and semiotic conflicts}

In this research we will try to explain the prospective teachers' difficulties in computing simple, compound and conditional probabilities in the task given to them using two assumptions. Firstly we will use the idea of semiotic conflict defined by Godino, Batanero, and Font (2007) as a disparity between the student's interpretation of a mathematical expression and the meaning of the same expression in a mathematics or school institution. Secondly, we assume that some participants are unable to manage the whole complexity in the two-way table, and consequently need to reduce the information needed to solve the problem.

In order to clarify these assumptions, show the complexity of the two-way table, and also to analyze the teachers' responses to the task we will use some ideas from Godino et al. (2007), who suggested that different types of knowledge are put in practice when solving mathematical problems or communicating their solutions to other people. Godino et al. introduced the following classification of mathematical objects that are used in mathematical practices, and which will be used in this paper:

1. Language: words, symbols, graph used to represent the problem statement, the data and the operations carried out with these data. 
2. Problems: situations or mathematical applications, which can be internal or external to mathematics (for example, comparing two probabilities or assessin $g$ independence of two variables).

3. Concepts: given by their definitions (such as random experiment, outcome, sample space, simple or compound probability).

4. Propositions: properties or attributes of concepts (e.g., probability of complementary events; the product or addition rules of probability).

5. Procedures: operations, algorithms, techniques (such as division, addition, enumeration of the sample space or computing probabilities).

6. Arguments: used to validate and explain the propositions or the problems solution.

The six types of objects expand the traditional distinction between conceptual and procedural knowledge according to Godino et al. (2007). The problems promote and contextualize this activity; language represents the other entities and is a tool for action; arguments justify the procedures and propositions that relate the concepts. The authors take from Eco (1979) the notion of semiotic function, or correspondence (relation or function) between an antecedent (expression, signifier) and a consequent (content, signified or meaning), established by a subject (person or institution) according to certain criteria. The specific criteria linking expression and meaning in a semiotic function can be a mathematical rule or just a habit or agreement and informs the subjects implied in the interpretative process about the terms that should be put in correspondence in the fixed circumstances.

Sometimes the meaning that the teacher or the researcher assigns for a given mathematical expression is interpreted in a non-normative way by the student. Godino et al. (2007) described a semiotic conflict as an incorrect interpretation of a mathematical expression that produces errors. These errors are not due to lack of knowledge on the part of the student but to the fact that he/she was unable to adequately relate the two terms in a semiotic function. In this construct we do not assume resistance on the part of the student and consequently may be solved with adequate instruction. The identification of these conflicts is consequently an important step to improve the teaching of a topic.

\section{Previous research}

Three research topics are related to our study: (a) two-way tables; (b) teachers' probabilistic knowledge; and (c) conditional probability. All of them are very wide topics; here we will only briefly mention what is relevant to our own research.

\section{Two-way tables and conditional probability}

A two-way or contingency table serves to present in a summarised way the frequency distribution in a population or sample that is classified according to two statistical variables (an example is given in Table 1).

Research on two-way tables was started by Inhelder and Piaget (1955), who described the strategies used at different ages when judging association in tables that were formally equivalent to Table 1 . Following Piaget, many other researchers focused on students' strategies and conceptions when assessing association between the variables in rows and columns from the data presented in a two-way table (e.g., Batanero, Estepa, Godino, \& Green, 1996; Jenkins \& Ward, 1965; Smedslund, 1963). Results of these studies supported our view of the complexity of

Table 1. Simple $2 \times 2$ two-way table

\begin{tabular}{llll}
\hline & A & No A & Total \\
\hline B & $\mathrm{a}$ & $\mathrm{b}$ & $\mathrm{a}+\mathrm{b}$ \\
No B & $\mathrm{c}$ & $\mathrm{d}$ & $\mathrm{c}+\mathrm{d}$ \\
Total & $\mathrm{a}+\mathrm{c}$ & $\mathrm{b}+\mathrm{d}$ & $\mathrm{a}+\mathrm{b}+\mathrm{c}+\mathrm{d}$ \\
\hline
\end{tabular}


two-way tables, since people's performance in judging association in these task is, in general poor and there is a tendency to base the association judgments on the difference between confirmatory cases (cell $a$ in Table 1 ) and contradictory cases (cell $d$ ).

Also relevant for this study is the research related to conditional probability, such as that by Falk (1986) who remarked that many students do not adequately discriminate between the two different conditional probability, that is, $P(A \mid B)$ and $P(B \mid A)$ (fallacy of transposed conditional) and that some students confused joint and conditional probability.

\section{Teachers' probabilistic knowledge}

The scarce research related to prospective primary school teachers' understanding of probability indicates this understanding is weak. For example, Begg and Edward (1999) found that only about two-thirds of the in-service and preservice primary school teachers in their sample understood equally likely events and very few understood the concept of independence. Batanero, Godino, and Cañizares (2005) found three widespread probabilistic misconceptions in a sample of 132 pre-service teachers related to representativeness (Tversky \& Kahneman, 1982), equiprobability (Lecoutre, 1992) and the outcome approach (Konold, 1991). Fernandes and Barros (2005) study with 37 prospective teachers in Portugal suggested the teachers' difficulties to formulate events and to understand compound and certain events. In addition, these teachers frequently used additive reasoning to compare probabilities.

In relation to knowledge needed to teach probability, Stohl (2005) suggested that few teachers have prior experience with conducting probability experiments or simulations and many of them may have difficulties implementing an experimental approach to teaching probability. Similar results were found in Lee and Hollebrands's (2008) research, where, although the participant teachers engaged students in investigations based on probability experiments, they almost exclusively chose small samples sizes and rarely pooled class data or used representations supportive of examining distributions and variability across collections of samples; so they failed to address the heart of the issue.

The most relevant study for this research is that by Estrada and Díaz (2006), who asked 65 prospective primary school teachers after following a 60 hours long course in statistics education, to compute simple, compound and conditional probability from data presented in a two-way table. The authors found a variety of errors in the solutions provided by these teachers, including confusion between compound and conditional probability, confusion between an event and its complementary, confusion between probabilities with possible cases (absolute frequencies), and assuming independence in the data.

In our own research Common content of elementary probability is assessed using a modified version of the problem proposed by Estrada and Díaz to a bigger sample of prospective teachers, with lower probabilistic training. Another difference is the semiotic analysis of the task and of participants' responses and the consequent identification of semiotic conflicts. This type of study was not performed by Estrada and Díaz.

A preliminary summarized version of quantitative results from this research was presented in a conference (Contreras, Batanero, Diaz, \& y Fernandes, 2011). In this paper we complement that paper with a qualitative semiotic analysis and provide a classification of semiotic conflicts that was not included in Contreras et al. 


\section{METHOD}

\section{Sample and educational context}

The sample in the study consisted of 183 prospective primary school teachers at the Faculty of Education, University of Granada, Spain. The task analyzed in this paper was answered individually by each participant as a part of the final assessment in a course of Mathematics Education. In this course (60 teaching hours), the prospective teachers were introduced to the primary school mathematics curriculum, didactic resources, children's difficulties, and technological tools for teaching elementary mathematics. Most sessions were devoted to practical work, in which participants performed didactic analyses of curricular guidelines, school textbooks, assessment items and children responses to these items, and teaching episodes, including identification of mathematical content and classification of mathematical objects according to Godino et al. (2007) model. Three sessions of the course were devoted to probability and statistics education. The previous year all these prospective teachers took a Mathematics course (90 teaching hours) with about 10 hours of in-classroom work devoted to statistics and probability (data, distribution, graphs, averages, variation, randomness and probability, including some exercises of compound and conditional probability).

\section{Assessment task}

The task given to participants is presented in Figure 1 and is adapted from Estrada and Díaz (2006), although the statement was simplified, in order to avoid the use of negative statements in the wording of the item and the use of inequalities in the definition of the sample space. The three questions in the task were aimed to assess the prospective teachers' CCK in relation to elementary probability. More specifically we were interested in the prospective teachers' ability to read the table and identify the data needed to compute a simple probability (question a), a compound probability (question b) and a conditional probability (question c).

In paragraph (a) the simple probability for event $A=\{$ liking tennis $\}$ is required. In order to solve the problem the prospective teacher has to read the table, identify the favourable and possible cases for the requested event, and apply Laplace's Rule. The number of possible cases is the sample size, and the number of favourable cases a marginal absolute frequency. The probability of liking tennis, $P(A)$ is obtained by dividing $a+b=600$ (number of boys and girls liking tennis) by the total $a+b+c+d$ $=700$, so that $P(A)=600 / 700=0.857$. In Table 2 we reproduce a semiotic analysis of this solution.

\begin{tabular}{|c|c|c|c|}
\hline \multicolumn{4}{|c|}{ A survey in a small school provided the following results: } \\
\hline & Boys & Girls & Total \\
\hline Liking tennis & 400 & 200 & 600 \\
\hline Disliking tennis & 50 & 50 & 100 \\
\hline Total & 450 & 250 & 700 \\
\hline \multicolumn{4}{|c|}{$\begin{array}{l}\text { Providing that we select one of the school students at random: } \\
\text { a. What is the probability that the student likes tennis? } \\
\text { b. What is the probability that the student is a girl and likes tennis? } \\
\text { c. The student selected is a girl. What is the probability that she likes tennis? }\end{array}$} \\
\hline
\end{tabular}

Figure 1. Task given to participants in the study 
In this solution concepts (random experiment, event, possible and favourable cases, total, sum and division, double and marginal absolute frequency), procedures (addition, division, Laplace's rule), numerical, symbolic, and verbal representations are brought into play, all of them linked in an argument. Consequently the person solving the problem should perform multiple interpretation and representation processes, as well as particularization of concepts. Solving the problem step by step moreover involves a process of decomposition or analysis, while the final conclusion reached is achieved through a synthesis process.

In paragraph (b) the joint probability of $A$ and $B$ is required. The person answering this part has to understand that the events are dependent, i.e., needs to read the table and perform a judgment of association in the data. He/she should then identify in the table the absolute frequency for the simultaneous occurrence of the two events, which is number of favourable cases. Like in paragraph (a), the number of possible cases is given by the sample size. By applying Laplace's rule the student would obtain $P(A \cap B)=b /(a+b+c+d)=200 / 700=2 / 7=0.28$. In Table 3 , we reproduce a semiotic analysis of this solution, in which the mathematical objects and

Table 2. Semiotic analysis for the correct solution to part (a)

A survey in a small school provided the following results:

\begin{tabular}{|c|c|c|c|c|}
\hline & & & & \\
\hline & Boys & Girls & Total & \\
\hline $\begin{array}{l}\text { Liking } \\
\text { tennis }\end{array}$ & 400 & 200 & 600 & $\begin{array}{l}\text { He/she should identify two categorical variables (concept) and establish a } \\
\text { correspondence (procedure) between the codes (boys, girls, liking/disliking }\end{array}$ \\
\hline $\begin{array}{l}\text { Disliking } \\
\text { tennis }\end{array}$ & 50 & 50 & 100 & $\begin{array}{l}\text { tennis) and the variables values (concept) and between these codes and an } \\
\text { imaginary sample of boys and girls (phenomenological element). }\end{array}$ \\
\hline Total & 450 & 250 & 700 & $\begin{array}{l}\text { He/she should identify the double and marginal frequencies and the sample } \\
\text { size (concepts and procedure; particularization to the situation). }\end{array}$ \\
\hline $\begin{array}{l}\text { e proba } \\
\text { nnis? }\end{array}$ & g tha & e & $\begin{array}{l}\text { of } \\
\text { lat is } \\
\text { es }\end{array}$ & $\begin{array}{l}\text { - He/she should interpret the question as referring to a random experiment } \\
\text { (picking a student at random from the whole sample), which involves } \\
\text { interpretation and particularization of mathematical concepts. } \\
\text { He/she should identify the sample space in the experiment (each student) and } \\
\text { the compound events (liking /disliking tennis) as well as the simple } \\
\text { probability requested in part (a) (concept; particularization to the situation). }\end{array}$ \\
\hline$(A)=(b$ & $b+c$ & 600 & $=0.857$ & $\begin{array}{l}\text { - He/she should identify the number of favourable cases (marginal frequency) } \\
\text { by particularizing some concepts; chose an adequate notation } b+d \text { (in which } \\
\text { also the addition procedure is represented). } \\
\text { He/she should also identify and represent the number of possible cases } a+b+ \\
c+d \text {, that is, the sample size and finally apply Laplace's rule, by dividing the } \\
\text { number of favourable cases between the number of possible cases } \\
\text { (procedure). }\end{array}$ \\
\hline
\end{tabular}

Table 3. Semiotic analysis for the correct solution to part (b)

\begin{tabular}{|c|c|}
\hline Expression & Content \\
\hline $\begin{array}{l}\text { What is the probability that the student is } \\
\text { a girl and likes tennis? }\end{array}$ & $\begin{array}{l}\text { - The person answering this part should identify the sample space in the } \\
\text { compound experiment (boy liking tennis; girl liking tennis, boy disliking } \\
\text { tennis; girl disliking tennis), as well as the compound probability requested } \\
\text { in part (b) by particularizing some concepts }\end{array}$ \\
\hline$P(A \cap B)=\frac{b}{a+b+c+d}=$ & $\begin{array}{l}\text { - He/she should identify the favourable cases } b \text { (joint frequency) by } \\
\text { particularizing some concepts and chose an adequate notation. }\end{array}$ \\
\hline$\frac{200}{700}=\frac{2}{7}=0.28$ & $\begin{array}{l}\text { associated (performing an association judgment), since otherwise he/she } \\
\text { should apply the product rule for independent events } \\
\text { He/she should also identify and represent the number of possible cases } \\
a+b+c+d \text {, and apply Laplace's rule. He/she represents the intersection } \\
\text { (concept and representation). } \\
\text { Finally the student performs the operation, simplifies and transforms the } \\
\text { rational number to decimal format. }\end{array}$ \\
\hline
\end{tabular}


processes described in analysis of the first question, as well as the concepts of join probability, compound sample space and events, and joint relative frequency intervene. Again the person solving the problem should interpret and represent concepts and properties, apply procedures and link all the solution using analysis and synthesis process.

The third question requires to compute the conditional probability of $B$ given that $A$ happened, $P(B \mid A)=b /(b+d)$, which is obtained by dividing $b=200$ (number of girls who like tennis) between $b+d=250$ (number of girls). The person answering this part should identify the favourable and possible cases in the table, and realize that the condition means a restriction of the sample space. Consequently, $P(B \mid A)=$ $200 / 250=4 / 5=0.8$. In Table 4 we reproduce the semiotic analysis. We remark that all the previous mathematical objects and processes, in addition to conditional probability, condition and conditioned (concepts), discrimination of a conditional probability and its transpose (property) and the related notation appear in this part of the task.

We note that Table 1 is a complex semiotic object, since each cell refer to the joint absolute frequency for a double condition (values of row and column) and from each we can deduce different relative frequencies and probabilities (simple, compound and conditional). In order to solve each part of the problem the subjects need to select adequate information. The problem statement contains the keys that induce this selection, which also depends on the subject's knowledge of probability. Our assumption is that some subjects may tend to reduce this complexity and use only a reduced number of cells; due to some semiotic conflicts that induce biases in the selection of information. Consequently these subjects would use the scheme of simple experiment and would organise the situation using only a simple sample space with two complementary events, instead of considering the four different possible simple events in the compound experiment.

For example, in part (a) a participant may only use the information in a column (e.g., consider only the boys, instead of the whole sample) and compute P(liking tennis $)=400 / 450$; that is the conditional probability of a boy liking tennis, instead of the simple probability of liking tennis $(600 / 700)$. This same strategy may be used in part (b) if the subject takes into account the data in only the row of those liking tennis to provide the solution $P$ (being a girl and liking tennis $)=200 / 600$, instead of $50 / 700$. In addition students may confuse mathematical objects or their properties interpreting them in a way different to what is intended by the teacher (semiotic conflict). Some semiotic conflicts may involve confusion between different types of probabilities, between an event and its complement or between other mathematical objects; all of them are failures in the interpretative processes carried out along the problem solving process.

Table 4. Semiotic analysis for the correct solution to part (c)

\begin{tabular}{ll}
\hline Expression & Content \\
$\begin{array}{l}\text { The student selected is a girl. What } \\
\text { is the probability that she does } \\
\text { like tennis? }\end{array}$ & $\begin{array}{l}\text { The person answering this part should identify conditional probability } \\
\text { requested in part (c); He/she should identify which is the condition and } \\
\text { which the event and be able to discriminate between } P(A / B) \text { and } P(B / A) \text { by } \\
\text { particularizing some concepts to the situation. }\end{array}$ \\
$P(B \mid A)=\frac{200}{250}=\frac{4}{5}=0.8$ & $\begin{array}{l}\text { He/she should identify the favourable cases (joint frequency) and chose an } \\
\text { adequate notation } b \text {, identify and represent the possible cases } a+b+c+d, \\
\text { and apply Laplace's rule. He should represent the conditional probability } \\
\text { and the operations. }\end{array}$ \\
\hline
\end{tabular}




\section{RESULTS AND DISCUSSION}

The written reports produced by the participants in the study were analyzed and the answers to each question were categorized, taking into account the correctness of the response, as well as the type of semiotic conflicts, in case of incorrect response. A full semiotic analysis for an example of response in each category, similar to that presented in Tables 2-4 was carried out in order to discover the support for our assumptions. Below we describe the main categories of responses and the semiotic conflicts involved; however, due to restriction in length we will only present the complete analysis for an example of incorrect answer (see Table 5); a summary of the semiotic analysis for the remaining categories of incorrect responses is included, instead of presenting the full analysis.

\section{Correct answers or minor mistakes}

We group in this category those answers where the prospective teachers in the sample correctly read the two-way table, identified the probability required and provided a correct solution to the problem. Some examples are provided in the response analyzed in Tables 2, 3 and 4 . We also include in this category those responses that provided a correct numerical result, with some computations mistakes, such as the following response to compute the probability of liking tennis:

$\begin{array}{l}700 \rightarrow 100 \\ 600 \rightarrow x\end{array} \quad x=\frac{600 \times 100}{700}=99 \%$ (Subject 43$)$.

\section{Confusing probabilities}

A first category of semiotic conflicts appears when the type of probability requested is confused in interpreting the question of the problem. The confusion between simple, compound and conditional probability in a similar task was also described by Estrada and Díaz (2006). An example in part a) is the following response:

“Probability that the person likes tennis is: $\left\{\begin{array}{l}\text { Boy: } \frac{4}{6}=66.6 \% \\ \text { Girl: } \frac{2}{6}=33.3 \%\end{array}\right.$

In the example, Subject 36 tried to reply to question (a), but, instead of computing a simple probability, he computed two conditional probabilities: the probability of being a boy and the probability of being a girl in case that the students

Table 5. Semiotic analysis for and incorrect solution to part (a) with confusion of probabilities

\begin{tabular}{|c|c|}
\hline Expression & Content \\
\hline $\begin{array}{l}\text { Probability that the person likes } \\
\text { tennis is: } \\
\left\{\begin{array}{l}\text { Boy: } \frac{4}{6}=66.6 \% \\
\text { Girl: } \frac{2}{6}=33.3 \%\end{array}\right.\end{array}$ & $\begin{array}{l}\text { - The student uses the ideas of random experiment, favourable and possible } \\
\text { cases (concepts) } \\
\text { - He performs a representation process to represent the events (Boy and } \\
\text { Girl); there is an incorrect use of the equal sign; then an incorrect process of } \\
\text { interpretation (semiotic conflict in applying a representation) } \\
\text { - } \quad \text { It is not clear that the student distinguish probability and percent } \\
\text { - He identifies the favourable cases a and b that correspond to join } \\
\text { frequencies (particularization of concepts) } \\
\text { - He identifies the possible cases } a+b \text { or marginal frequencies of those liking } \\
\text { tennis (particularization of concepts) } \\
\text { - He applies the Laplace rule (procedure) } \\
\text { - Instead of computing the probability of liking tennis (simple probability) he } \\
\text { computes two conditional probabilities: the probability of being a boy and } \\
\text { the probability of being a girl in case that the students liked tennis. There is } \\
\text { a semiotic conflict in confusing simple and conditional probability }\end{array}$ \\
\hline
\end{tabular}


liked tennis. This solution, analyzed in Table 5, is consistent with our assumption that the solver is unable to manage the whole data and works with the rows of the table one by one; he consequently uses a model of simple experiment to compute the probability and is unable to combine these two solutions by using the total probability rule. He therefore, provides two different solutions. We can also observe that this prospective teacher did not reach the "reading data" level (Curcio, 1989) since was unable to read the data in the two-way table to find a marginal frequency; consequently he could not give a simple solution to the problem.

The most frequent confusion in this category $(13.7 \%$ of participants in the sample) was between conditional and compound probability: For example, replying in the second part of the problem: "Probability of liking tennis and being a girl is 2/6=33,33\%" (Subject 143). In this example, we see how the prospective teacher computes a conditional probability, the probability of being a girl in case the student likes tennis. This is an error described by Ojeda (1995), and by Falk (1986) in university students and also was found in $17 \%$ of prospective teachers in Estrada and Díaz's research. In the context of two-way tables, this error may also be explained by our previous assumptions, since the solver only uses the row corresponding to $A$ and then compute $a /(a+b)$, that is, a conditional probability $P(B / A)$, instead of computing $P(A \cap B)$, where the four cells are needed in order to compute the denominator in Laplace's rule.

A few participants confused $P(A \mid B)$ and $P(B \mid A)$, an error that was termed by Falk (1986) as the fallacy of the transposed conditional. In the third part of the problem, these participants would compute a wrong conditional probability: "There is 33\% probability that a girl likes tennis" (Subject 71), since they did not adequately discriminate the two different conditional probabilities $P(A \mid B)$ and $P(B \mid A)$. In the example, the participant computes the probability of being a girl, when we know that the student likes tennis $(200 / 600)$.

Similarly to the study of Estrada and Díaz (2006) other participants confused simple and compound probability; and then in part b) of the task computed two simple probabilities: "The probability of being a girl and liking tennis is 41.6\% the probability of being a girl and 80\% the probability of liking tennis" (Subject 92).

Finally, other prospective teachers confused simple probability with the probability of an elementary event: "Probability of liking tennis if you select a student at random is 1/700, since there are 700 students" (Subject 82 ). This teacher assumed all the elements in the sample to be equiprobable, and assigned each of them an identical probability; instead of computing the simple probability of liking tennis, he computed the probability of taking a particular student at random. This type of error was not described in previous research.

\section{Confusing events}

A few prospective teachers identified the probability but made a semiotic conflict when interpreting the description of the event for which the probability was requested an error described by Estrada and Díaz (2006). Again this conflict suggests these pre-service teachers' inability to read the two-way table, and that some did not reach the elementary level of "reading data" described by Curcio (1989).

These participants confused an event and its complement, as for example, Subject 102 in her response to part c): "The probability of liking tennis being a girl is 50/250 $=20 \% "$. In this example, the participant correctly identified that the computation of a conditional probability was needed and applied the correct formula; although she confused the event in the numerator and computed $P\left(B^{C} / A\right)=50 / 250$ instead of $P(B / A)=200 / 250$. She therefore is considering the girls who do not like tennis, instead of the girls liking tennis. 


\section{Confusing other mathematical objects}

Other prospective teachers exchanged probability and number of favourable cases. An example related to question (a) is: " $P(A=400+200=600$ " (Subject 29). This participant identified the probability to be computed, read the table and identified the marginal frequency, but he did not divide the favourable cases by the total sample size to compute a probability. Therefore he obtained a probability higher than 1 and did not discriminate the elementary properties of probability (forgetting that a probability can never be higher than 1 ).

Other participants combined probability and percentages in their formulas and due to this mixture also got probabilities higher than 1; again being unconscious of probability axioms. In the following example the participant applied Laplace's rule and then multiplied by 100: "The probability that a student likes tennis is 600/7" (Subject 52).

Another conflict also found by Estrada and Díaz (2006) was assuming independence in the data, although dependence was clear in the table. In these cases, the prospective teachers remembered the product rule, but did not discriminate the correct application in case of dependence and independence. Consequently they computed the joint probability as the product of $P(A)$ and $P(B)$, getting the following solution: "Probability of being an girl and liking tennis = $P(A \cap B)=\frac{250}{700} \times \frac{600}{700} "$ (Subject 22).

\section{Confusing formulas}

Some prospective teachers were able to correctly identify the probability that was requested in each part of the problem and also used correct symbols to express these probabilities; however they interpreted in non-conventional ways the formulas to compute the probabilities, and consequently the final result was wrong. Some examples are given below:

1. Misapplication of Laplace's rule. An example in the second part of the problem is: $" P(A \cap B)=\frac{\text { number of cases favourable to } \mathrm{A} \cap \mathrm{B}}{\text { number of cases favourable to }\left(\mathrm{A}^{\mathrm{C}} \cap \mathrm{B}\right) 700}=\frac{200}{400} " \quad$ (Subject $\quad 54$ ). This participant interpreted correctly question (b) of the problem, correctly read the table data, and used a correct notation for the joint probability. She also identified the number of cases favourable as $A \cap B$, however, instead of dividing by the number of possible cases he divided by the number of unfavourable cases. This involves a routine learning of the Laplace's rule, without a grasping of its meaning.

2. Using the formula $P(A \cap B)=P(A \cap B) P(A \mid B)$. In this case, the subject remembered that the conditional probability $P(A \mid B)$ intervenes in the product rule when the events are dependent and was able to identify the dependence between $A$ and $B$ in this problem. However, he changed the simple probability $P(B)$ by the joint probability $P(A \cap B)$ in the product rule. An example is as follows: "There are 250 girls among the 700 students; 200 of them like tennis. Therefore, if we pick at student at random, the probability of being a girl and liking tennis is $\frac{200}{700} \times \frac{200}{259}=$ $\frac{5}{49}$ ” (Subject 183).

3. Computing $P(A \cap B)=P(A) \times P(A \mid B)$. In the following example the participant correctly interprets the question and remembers the product rule in the case of dependence. However, he confuse the terms in the conditional probability in the formula (transposed conditional fallacy). "The probability of being a girl and liking tennis is:

$P($ GirlnLiking tennis $)=P($ Girl $) P($ Girl $/$ liking tennis $)=\frac{250}{700} \times \frac{200}{600}=\frac{5}{42}{ }^{\prime}($ Subject 93 $)$. 
4. Assuming the same proportion of girls and boys in the sample: "Probability of being a girl and liking tennis: $P(A) \times P(A / B)=\frac{1}{2} \times \frac{200}{600}$ " (Subject 165). This subject does not read the data for the proportion of boys and girls in the sample. Once he identifies the correct probability to be computed and uses the correct formula, he correctly computes the joint probability by the usual proportion of males and females $(1 / 2)$ without noticing that, in this sample, this proportion does not apply.

5. Computing $P(A \cap B)=P(A)+P(A \cap B)$, that is, using addition instead of multiplication in the product rule: An example is as follows: "Probability of liking tennis and being a girl is $P=\frac{2.5}{7}+\frac{2}{7}=\frac{4.5}{7}$ "' (Subject 171).

6. Computing the probability for an event and adding the probability of its complement. This response implies a poor understanding of probability and its properties, since the probability of a part of the sample space should be lower than 1 . Moreover, the subject forgets an axiom by which when adding the probability for an event and its complement you always get the unity. An example of this response in the first part of the problem is as follows: "The probability of liking tennis is $\frac{400}{600}+\frac{200}{600}=\frac{600}{600}$, (Subject 164$)$.

In addition to these errors, other prospective teachers built an incorrect tree diagram, and then were unable to use it to finish the solution or computed the average frequency in the table.

\section{Summary of results}

In Table 6, we present the prospective teachers' responses to each part of the problem, using the following abbreviations: $A=$ "the student likes tennis"; $B=$ "the student is a girl". The percentage of correct responses or responses with minor errors is low, except for question (a) (65.6\% of the sample), in agreement with what was reported by Estrada and Díaz in their sample. Although the majority of participants correctly computed simple probability, less than $45 \%$ of responses in question (b) (computing joint probability) and (c) (computing conditional probability) were correct.

The percentage of pre-service teachers confusing different probabilities was slightly lower than that reported by Estrada and Díaz (2006), possibly because the task was simplified. Also, similarly to Estrada and Díaz's research, an important percentage of participants in our study did not provide any solution. There were a variety of errors reported in previous research, in particular confusion between different probabilities, while, at the same time, we found other errors, such as confusing a simple probability with the probability of an elementary event, a mistake which was only described in our previous analysis (Contreras, Batanero, Diaz y Fernandes, 2011).

In Table 7 we classify the different semiotic conflicts involved in the participants' responses to the three tasks, where a participant may present a conflict in more than

Table 6. Frequency (and percentage of students) of responses to the three questions

\begin{tabular}{llll}
\hline Teacher's answer & $\mathbf{P}(\mathbf{A})$ & $\mathbf{P}(\mathbf{A} \cap \mathbf{B})$ & $\mathbf{P ( A / B )}$ \\
\hline Correct or minor mistakes & $120(65.6)$ & $75(41.0)$ & $80(43.7)$ \\
Confuse probabilities & $8(4.4)$ & $45(24.6)$ & $30(16.4)$ \\
Confuse events & $0(0.0)$ & $2(1.1)$ & $2(1.1)$ \\
Confuse other mathematical objects & $9(4.9)$ & $10(5.5)$ & $5(2.7)$ \\
Confuse formulas & $3(1.6)$ & $14(7.7)$ & $8(4.4)$ \\
Other errors & $9(4.9)$ & $4(2.2)$ & $15(8.2)$ \\
Do not provide an answer & $34(18.6)$ & $33(18.0)$ & $43(23.5)$ \\
Total & $183(100)$ & $183(100)$ & $183(100)$ \\
\hline
\end{tabular}


Table 7. Frequency of different semiotic conflicts in the three tasks

\begin{tabular}{lc}
\hline Type of conflict & Frequency \\
\hline Confusing joint and conditional probability & 39 \\
Confusing simple probability with joint probability & 7 \\
Confusing simple probability with conditional probability & 13 \\
Confusing simple probability with probability of an elementary event & 18 \\
Confusing a conditional probability and its transposed & 12 \\
Confusing probabilities and frequencies & 16 \\
Confusing favourable or unfavourable and possible cases & 9 \\
Confusing union and intersection & 3 \\
Assuming independence & 3 \\
Confusing an event and its complement & 5 \\
Obtaining a probability higher than 1 & 23 \\
Confusing formulas & 18 \\
Computation errors, do not identify data or incorrect reading of the table & 31 \\
Total number of conflicts in all the responses & 197 \\
\hline
\end{tabular}

a task or more than a conflict in one of the task. For example, a prospective teacher who computes $P\left(A^{C} \cap B\right)$ instead of $P(B \mid A)$ first confused conditional and joint probabilities; while at the same time confused and event and its complement. When dividing the sum of all these conflicts between the number of prospective teachers, we obtain an average value of 1.07 conflicts per prospective teacher in the three tasks; while if we only take into account the responses (439 in the three tasks) we obtain an average value of 0.45 per response provided. That can be interpreted as a conflict in one of the task per prospective teachers and $45 \%$ of the non-blank responses containing a conflict.

We observe that the confusion between joint and conditional probability or the fallacy of the transposed conditional described by Falk (1986) were the most frequent errors in our sample, but, even though they do not explain alone the high percent of incorrect responses in computing joint and conditional probabilities (about 40\%). There were also some prospective teachers who obtained probabilities higher than one, without noticing the inconsistency; others applied wrong formulas, confused simple with joint or conditional probability, or confused simple probability with the probability of an elementary event probabilities. Less frequent was the confusion of frequencies with probability, favourable and possible cases, an event and its complement. Finally some prospective teachers did not identify the probability to be computed, used an incorrect formula, were unable to read the table and find the data needed or were unable to produce a solution.

\section{CONCLUSIONS AND IMPLICATIONS FOR TRAINING THE TEACHERS}

Our results suggest that computing simple, compound and conditional probabilities from a two-way table was not easy for participants in the sample who showed a weak common knowledge of probability to solve this task. Many teachers were unable to provide a correct answer to the problems, in agreement with Estrada and Díaz's (2006) research, or made errors reported in previous research, particularly by Falk (1986). Along the paper we used the idea of semiotic conflicts to explain errors reported in previous research as well as our assumption that subjects reduce the information needed to solve the problem and use only a row or column in the table to give the solution as they are unable to manage the information complexity in these tables. This bias reduces the compound experiment to a simple experiment and the sample space to an event and its complement.

In our research, some new conflicts appear, that have been not reported in previous research, and which are not explained by this bias, but are due to confusion between simple probability and probability of an elementary event, confusion between mathematical objects (e.g. probabilities and frequencies), confusion of an 
event, difficulties in reading the two-way table and confusion in formulas also were frequent.

These results are cause for concern, since prospective teachers in our sample are likely to fail in future teaching of probability in some professional activities, such as "figuring out what students know; choosing and managing representations of mathematical ideas; selecting and modifying textbooks; deciding among alternative courses of action" (Ball, Lubienski, \& Mewborn, 2001, p. 453). These activities involve mathematical reasoning and thinking, which were weak for these teachers when dealing with probability. We agree with Falk that the everyday language we use to state a conditional probability problem lacks precision and is therefore ambiguous. However, a future teacher should master both the concept and the language used in teaching, particularly the language which today is part of statistical literacy, which is important for their students, and which they should transmit them. To conclude these results suggest the need to reform and improve the probability education these future teachers are receiving during their training in the schools of education.

\section{ACKNOWLEDGEMENT}

Project EDU2013-41141-P (MEC, Madrid), and Group FQM126 (Junta de Andalucía).

\section{REFERENCES}

Ball, D. L., Lubienski, S. T., \& Mewborn, D. S. (2001). Research on teaching mathematics: The unsolved problem of teachers' mathematical knowledge. In V. Richardson (Ed.), Handbook of research on teaching (pp. 433-456). Washington, DC: American Educational Research Association.

Batanero, C., Estepa, A., Godino, J. D., \& Green, D. R. (1996). Intuitive strategies and preconceptions about association in contingency tables. Journal for Research in Mathematics Education, 27(2), 151-169.

Batanero, C., Godino, J. D., \& Cañizares, M. J. (2005) Simulation as a tool to train Pre-service School Teachers. In J. Addler (Ed.), Proceedings of ICMI First African Regional Conference [CD]. Johannesburg, South Africa: International Commission on Mathematical Instruction.

Begg, A., \& Edwards, R. (1999, December). Teachers' ideas about teaching statistics. Paper presented at the Annual Meeting of the Australian Association for Research in Education and the New Zealand Association for Research in Education. Melbourne, Australia.

Contreras J. M., Batanero, C. Diaz, C, y Fernandes, J. A. (2011). Prospective teachers' common and specialized knowledge in a probability task. In M. Pytlak, T. Rowland, \& E. Swoboda (Eds.), Proceedings of the Seventh Congress of the European Society for Research in Mathematics Education (pp. 766-765). Rzeszow, Poland: European Society for Research in Mathematics Education. Retrieved from http://www.mathematik.unidortmund.de/ erme/doc/cerme7/CERME7.pdf

Curcio, F. R. (1989). Developing graph comprehension. Reston, VA: National Council of Teachers of Mathematics.

Eco, U. (1979). Tratado de semiótica general [Treatise of general semiotics]. Barcelona, Spain: Lumen.

Eichler, A. (2011). Statistics teachers and classroom practices. In C. Batanero, G. Burrill, \& C. Reading (Eds.), Teaching Statistics in School Mathematics-Challenges for Teaching and Teacher Education (pp. 175-186). New York, NY: Springer.

Estrada, A., \& Díaz, C. (2006). Computing probabilities from two way tables: an exploratory study with future teachers. In A. Rossman \& B. Chance (Eds.), Proceedings of the Seventh International Conference on Teaching Statistics. Salvador (Bahia, Brazil): International Association for Statistical Education. Retrieved from http://iaseweb.org/Conference_Proceedings.php?p=ICOTS_6_2002. 
Falk, R. (1986). Conditional probabilities: insights and difficulties. In R. Davidson, \& J. Swift (Eds.), Proceedings of the Second International Conference on Teaching Statistics (pp. 292-297). Victoria, Canada: International Statistical Institute. Retrieved from http://iase-web.org/Conference_Proceedings.php?p=ICOTS_2_1986.

Fernandes, J. A., \& Barros, P. M. (2005). Dificuldades de futuros professores do $1^{\circ}$ e $2^{\circ}$ ciclos em estocástica (Pre-service primary school teachers difficulties in stochastics). In Actas do $V$ Congresso Ibero-Americano de Educação Matemática (CIBEM) [CD]. Porto (Portugal): Faculdade de Ciências.

Franklin, C., Kader, G., Mewborn, D.S., Moreno, J., Peck, R., Perry, M., \& Scheaffer, R. (2007). A Curriculum Framework for K-12 Statistics Education. GAISE Report. Retrieved from http://www.amstat.org/education/gaise/.

Franklin, C., \& Mewborn, D., 2006. The statistical education of PreK-12 teachers: A shared responsibility. In G. Burrill (Ed.), Thinking and reasoning with data and chance NCTM 2006 Yearbook (pp. 335-344). Reston, VA: National Council of Teachers of Mathematics.

Gal, I. (2005). Towards "probability literacy" for all citizens: building blocks and instructional dilemas. In G. Jones (Ed.), Exploring probability in schools: challenges for teaching and learning (pp. 39-63). New York, NY: Springer.

Godino, J. D., Batanero, C., \& Font, V. (2007). The onto-semiotic approach to research in mathematics education. ZDM- The International Journal on Mathematics Education, 39(1-2), 127-135.

Hill, H. C., Ball, D. L., \& Schilling, S. G. (2008). Unpacking pedagogical content knowledge: Conceptualizing and measuring teachers' topic-specific knowledge of students. Journal for Research in Mathematics Education, 39, 372-400.

Inhelder, B., \& Piaget, J. (1955). De la logique de l'enfant a la logique de l'adolescent (From the logic of children to the logic of adolescent). Paris: Presses Universitaries Framçaises.

Jenkins, H. M., \& Ward, W. C. (1965). Judgement of contingency between responses and outcomes. Psychological Monographs, 79.

Jones, G. (2005). Introduction. In G. Jones (Ed.), Exploring Probability in School: Challenges for Teaching and Learning (pp. 1-12). New York, NY: Springer.

Konold, C. (1991). Understanding students' beliefs about probability. In E. von Glasersfeld (Ed.), Radical constructivism in mathematics education (pp. 139-156). Dordrecht, The Netherlands: Kluwer.

Lecoutre, M. P. (1992). Cognitive models and problem spaces in "purely random" situations. Educational Studies in Mathematics, 23, 557-568.

Lee, H. S. \& Hollebrands, K. (2008). Preparing to teach data analysis and probability with technology. In C. Batanero, G. Burrill, C. Reading, \& A. Rossman (Eds.) Joint ICMI/IASE Study: Teaching Statistics in School Mathematics. Challenges for Teaching and Teacher Education. Proceedings of the ICMI Study 18 and 2008 IASE Round Table Conference. Monterrey: ICMI and IASE. Retrieved from http://iaseweb.org/Conference_Proceedings.php?p=Joint_ICMI-IASE_Study_2008.

MEC (2006). Real Decreto 1513/2006, de 7 de Diciembre, por el que se establecen las Enseñanzas Mínimas de la Educación Primaria [Curricular guidelines for primary education]. Madrid: Author.

MECD (2014). Real Decreto 126/2014, de 28 de febrero, por el que se establece el currículo básico de la Educación Primaria [Curricular guidelines for primary education]. Madrid, Spain: Author.

NCTM (2000). Principles and standards for school mathematics. Reston, VA: Author. Retrieved from http://standards.nctm.org/

Shulman, L. S. (1987). Knowledge and teaching: Foundations of the new reform. Harvard Educational Review, 57, 1-22.

Smedslund, J. (1963). The concept of correlation in adults. Scandinavian Journal of Psychology, 4, 165-173.

Stohl, H. (2005). Probability in teacher education and development. In G. Jones (Ed.), Exploring probability in schools: Challenges for teaching and learning (pp. 345-366). New York, NY: Springer.

Tversky, A., \& Kahneman, D. (1982). Judgement of and by representativeness. In D. Kahneman, P. Slovic y A. Tversky (Eds.), Judgement under uncertainty: Heuristics and biases (pp. 84 - 98). Cambridge, MA: Cambridge University Press.

$$
\diamond \diamond \diamond
$$

